\title{
Results of surgery for atrial septal defect in patients of 40 years and over
}

\author{
MICHAEL KNIGHT ${ }^{1}$ and STUART LEN NOX \\ The Brompton Hospital, London S.W.3
}

\begin{abstract}
Surgical closure of an atrial septal defect was performed on 104 patients over the age of 40 at the Brompton Hospital. The hospital mortality was $9.6 \%$, reducing to $2 \cdot 7 \%$ in the last six years. There were five late deaths.

A moderate increase in preoperative pulmonary artery systolic pressure did not influence mortality. Twenty-five per cent of patients in preoperative atrial fibrillation have been maintained in sinus rhythm an average of five years following operation. Seven per cent of patients in sinus rhythm preoperatively left hospital in atrial fibrillation. Another $7 \%$ developed atrial fibrillation an average of seven years after operation.

At late follow-up 75 patients were symptom-free and leading normal lives. It is concluded that patients in this age group with atrial septal defect benefit from surgical closure of the defect.
\end{abstract}

Atrial septal defect is the commonest congenital heart lesion found in adults. Although the condition normally follows a benign course in early life, progressive disability in the fourth and fifth decades is the general rule, resulting in significant shortening of the lifespan (Campbell, Neill and Suzman, 1957 ; Burrett and White, 1945).

Surgical correction of this anomaly has become an established procedure, and in the younger age groups is associated with little morbidity and a

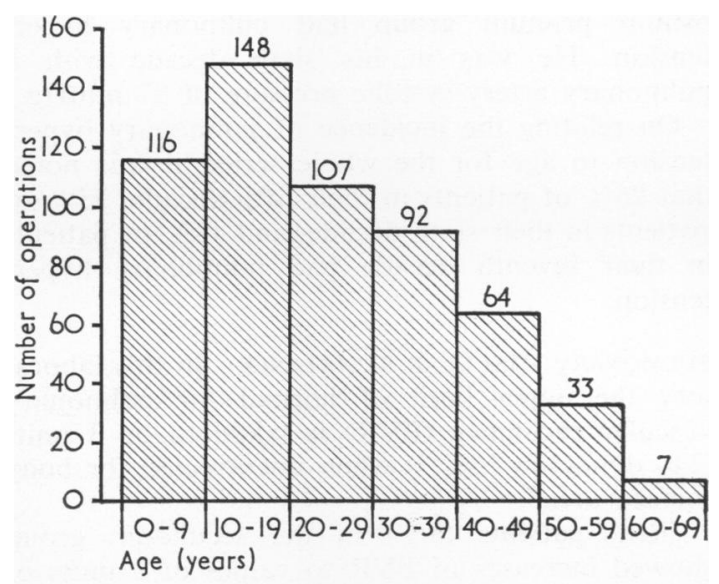

FIGURE. Atrial septal defect 1953-70. Number of operations related to age.

1Present address: St. George's Hospital, London S.W.1 low mortality (Cohn, Morrow, and Braunwold, 1967 ; Barratt-Boyes, 1963). However, there has bsen some reservation regarding the advisability of operation in the older age group, particularly in those patients with established severe pulmonary hypertension (Markman, Howitt, and Wade, 1965 ; Wolf, Vogel, Pryor, and Blount, 1968).

This study was undertaken to assess the experience at the Brompton Hospital in the surgical management of patients in this older age group with particular regard to postoperative morbidity and mortality.

\section{PATIENTS UNDER REVIEW}

Between 1953 and December 1970, 567 patients with atrial septal defect as their predominant lesion were treated surgically at this hospital (Figure). Of these, 104 patients were aged over 40 years at the time of operation. There were 64 in their fifth decade, 33 in their sixth decade, and seven in

T A B LE I

AGE AT OPERATION

\begin{tabular}{c|ccc|c}
\hline \multirow{2}{*}{$\begin{array}{c}\text { Age } \\
\text { (yr) }\end{array}$} & \multicolumn{3}{|c|}{ No. of Patients } & \multirow{2}{*}{ Total } \\
\cline { 2 - 4 } & Secundum & Primum & $\begin{array}{c}\text { Sinus } \\
\text { Venosus }\end{array}$ & \\
\hline $40-49$ & 55 & 3 & 6 & 64 \\
$50-59$ & 27 & 2 & 4 & 33 \\
$60-69$ & 7 & - & - & 7 \\
\hline
\end{tabular}


their seventh decade, the eldest patient being 66 years old (Table I). The commonest lesion was the secundum type and this occurred in 89 patients. Another 10 had a sinus venosus defect and the remaining five were of the ostium primum type.

\section{CLINICAL FEATURES}

Sixty-five per cent of the patients were female.

The majority of patients were symptomatic. Only $9.7 \%$ denied symptoms and these were referred following routine medical examination or routine chest radiography.

The commoner presentations were breathlessness on exertion (86\%), palpitations $(42 \%)$, and chest pain $(22 \%)$. A high incidence of symptoms occurred in those patients with ostium primum defects (Table II) and it was also noted that this group developed these symptoms a decade earlier than the secundum and sinus venosus groups (Table III).

On clinical examination $28 \%$ of all patients were in established dysrhythmias (atrial fibrillation $22 \%$, atrial flutter $3 \%$, supraventricular tachycardia $2 \%$, nodal rhythm $1 \%$, and complete heart block $1 \%$ ).

T A B L E II

SYMPTOMATOLOGY

\begin{tabular}{l|ccc|c}
\hline \multirow{2}{*}{ Symptom } & \multicolumn{4}{|c}{ Percentage of Defects } \\
\cline { 2 - 5 } & Secundum & Primum & Venosus & Total \\
\hline Breathlessness & 85 & 100 & 90 & 86 \\
Palpitations & 40 & 60 & 50 & 42 \\
Chest pain & 20 & 40 & 33 & 22 \\
\hline
\end{tabular}

T A B L E I I I

DURATION OF SYMPTOMS

\begin{tabular}{|c|c|c|c|}
\hline & \multicolumn{3}{|c|}{ Defect } \\
\hline & Secundum & Primum & $\underset{\text { Venosus }}{\text { Sinus }}$ \\
\hline $\begin{array}{l}\text { Average age at onset of symptoms } \\
\text { Average age at operation } \\
\text { Average duration of symptoms } \\
\text { (years) }\end{array}$ & $\begin{array}{r}43 \cdot 4 \\
48 \cdot 5 \\
5 \cdot 1\end{array}$ & $\begin{array}{l}33 \cdot 4 \\
47.8 \\
14.4\end{array}$ & $\begin{array}{r}44 \cdot 5 \\
48 \cdot 8 \\
4 \cdot 3\end{array}$ \\
\hline
\end{tabular}

TA B LE IV

INCIDENCE OF DYSRHYTHMIA AND CONGESTIVE HEART FAILURE

\begin{tabular}{l|ccc|c}
\hline & \multicolumn{4}{|c}{ Percentage of Defects } \\
\cline { 2 - 5 } & Secundum & Primum & $\begin{array}{c}\text { Sinus } \\
\text { Venosus }\end{array}$ & Total \\
\hline $\begin{array}{l}\text { Dysrhythmia } \\
\text { CHF }\end{array}$ & 28 & 20 & 33 & 28 \\
\hline
\end{tabular}

Twenty per cent of all patients were in congestive heart failure, as evidenced by a high central venous $\frac{\bar{\rho}}{\bar{a}}$ pressure and peripheral oedema (Table IV).

\section{INVESTIGATION}

Ninety-nine patients underwent cardiac catheteri- $\overrightarrow{\vec{\omega}}$ zation preoperatively to confirm the diagnosis, $\stackrel{\circ}{\circ}$ exclude or confirm co-existing defects, measure $\vec{x}$ the pulmonary artery pressure and pulmonary vascular resistance, and assess the degree of shunt. $*$ ir Five patients in the secundum group did not under-ir go cardiac catheterization.

PULMONARY ARTERY PRESSURE In this laboratory the upper limit of pulmonary artery systolic pres- $c$ s sure is taken as $35 \mathrm{mmHg}$ referable to the sternalo angle.

Ostium secundum group Twenty-seven patients $(33 \%)$ with secundum defects had pulmonary $\overrightarrow{0}$ hypertension. Of these patients 14 were in their N fifth decade, nine in their sixth decade, and four in their seventh decade. Four patients $(4.5 \%)$ showed elevations of pulmonary artery systolic pressure above $60 \mathrm{mmHg}$, the highest pressure recorded being $85 / 32 \mathrm{mmHg}$.

Sinus venosus group Three patients $(30 \%)$ with $\overrightarrow{\vec{O}}$ sinus venosus defects had pulmonary hypertension. 3 All were in their early forties. One patient $(10 \%)$ showed a pulmonary artery systolic pressure of $60 \mathrm{mmHg}$.

Ostium primum group One patient $(20 \%)$ in the $\underset{\times}{\stackrel{0}{\varpi}}$ ostium primum group had pulmonary hyper- $\dot{0}$ tension. He was in his sixth decade with a pulmonary artery systolic pressure of $37 \mathrm{mmHg}$.

On relating the incidence of pulmonary hyper- $₹$ tension to age for the whole series, it was noted 의 that $26 \%$ of patients in their fifth decade, $33 \%$ of $>$ patients in their sixth decade, and $43 \%$ of patientso in their seventh decade had pulmonary hyper- N tension.

PULMONARY VASCULAR RESISTANCE In this labora- N tory the upper limit of normal for pulmonary 0 vascular resistance (PVR) is taken to be 3 units $\left(240\right.$ dynes $/ \mathrm{sec} / \mathrm{cm}^{-5}$ ) when uncorrected for body surface area.

Eight patients $(9 \%)$ in the secundum group showed increases of PVR to values of 3 units or $\overline{0}$ over. Six of these patients were in their fifth $\mathbb{D}$ decade and two in their sixth decade. Only one $\mathbb{\Phi}$ patient $(10 \%)$ with a sinus venosus defect had an increased PVR. He was aged 40 with a PVR value 
of 4.6 units. No patient in the primum group showed an increased PVR.

SHUNT All but six patients had pulmonary/ systolic flow ratios of 2 to 1 or higher. In 23 patients the shunt was more than 4 to 1 , including 19 in the secundum group, three in the sinus venosus group, and one patient in the primum group.

\section{SURGICAL TECHNIQUE}

Surgical technique has changed over the years.

The earliest case was corrected by atrioseptopexy. Subsequently moderate hypothermia by veno-venous or surface cooling was employed. During 1963 and 1964 seven cases were operated upon under profound hypothermia by the Drew technique. Since 1965 only cardiopulmonary bypass has been used. In all, 45 patients underwent moderate hypothermia, seven profound hypothermia, and 51 cardiopulmonary bypass.

The method employed to close the defect depended on its size and anatomical type. Thus, in the secundum group closure by direct suture was possible in 86 patients. In only three was the defect considered large enough to require a patch. In the sinus venosus group the defect and associated partial anomalous pulmonary venous drainage were corrected in the seven earlier cases by direct suture. More recently it has been the practice to insert a patch of Teflon or pericardium with the patient on cardiopulmonary bypass.

Although the five patients with primum defects all had cleft mitral valves at operation, only two patients were considered to have significant mitral regurgitation on preoperative clinical assessment. In both of these cases the cleft was repaired by direct suture. All primum defects were closed with a pericardial patch.

Of the four patients with co-existing mitral stenosis, three underwent mitral valvotomy through the atrial septal defect with the use of Tubbs' dilator on two occasions and digital dilatation on the third. Mitral stenosis in the fourth patient was unsuspected, the diagnosis being made at necropsy.

\section{RESULTS}

HOSPITAL MORTALITY There were 10 deaths in the series within one month of operation, all in the secundum group. Six of these patients had their defects repaired under moderate hypothermia, three under cardiopulmonary bypass, and one under profound hypothermia.
Only one death has occurred in 37 defects repaired in the last six years under review, a hospital mortality of $2.7 \%$.

Of the six deaths following moderate hypothermia, three occurred during operation from irreversible ventricular fibrillation. One died 30 hours postoperatively in persistent ventricular fibrillation, while another died suddenly 10 days after operation from cardiac tamponade following the administration of prophylactic anticoagulants. The remaining death was also sudden eight hours following operation and was attributed to adrenal failure. This patient had been receiving preoperative prednisone for polyarteritis nodosa.

The one death following profound hypothermia occurred during operation from irreversible ventricular fibrillation. There were three deaths in the 51 patients operated upon under cardiopulmonary bypass. One died 24 hours postoperatively in persistent ventricular fibrillation. Another failed to regain consciousness after operation, developed a left hemiplegia, and died on the sixth postoperative day. The third death occurred in the fourth week during quinidine therapy for atrial fibrillation.

The relationship of various adverse preoperative factors to hospital mortality for the whole series is shown in Table V. It may be noted that a moderate elevation in pulmonary artery pressure (up to $60 \mathrm{mmHg}$ systolic) did not significantly increase the overall hospital mortality. In the seven patients with pulmonary artery pressures above $60 \mathrm{mmHg}$ there were two deaths, both following hypothermia in 1958 . Since that time there has been no hospital mortality in five patients in this group (average pulmonary artery systolic pressure of $72 \mathrm{mmHg}$ ).

Analysis of the eight patients from all groups with increased pulmonary vascular resistance shows that the two deaths in this group also occurred in 1958 and both were associated with severe pulmonary hypertension. Since then there

T A B L E V PREOPERATIVE FACTORS

\begin{tabular}{l|cc|cc}
\hline & \multicolumn{2}{|c|}{$1953-1964$} & \multicolumn{2}{c}{$1965-1970$} \\
\cline { 2 - 5 } & $\begin{array}{c}\text { No. of } \\
\text { Patients }\end{array}$ & $\begin{array}{c}\% \\
\text { Mortality }\end{array}$ & $\begin{array}{c}\text { No. of } \\
\text { Patients }\end{array}$ & $\begin{array}{c}\% \\
\text { Mortality }\end{array}$ \\
\hline Age 50+ & 23 & 17 & 17 & 6 \\
Dysrhythmias & 22 & 18 & 7 & 0 \\
Heart failure & 15 & 33 & 6 & 0 \\
Pulmonary artery pressure & 45 & $8 \cdot 8$ & 36 & 3 \\
Up to 35 mmHg systolic & 45 & 15 & 8 & 0 \\
36 to 59 mmHg systolic & 20 & 28 & 2 & 0 \\
60+ mmHg systolic & 7 & 28 & 1 & 0 \\
PVR > 3 units & 7 & & & \\
\hline
\end{tabular}


has been no hospital mortality in six patients with increased PVR (average PVR 4.5 units, range 3-5.8 units).

LATE DEATHS The period of follow-up ranged from four months to 13 years. Apart from seven cases lost to follow-up and those patients undergoing surgery in the last year, all patients were followed up for at least one year. The average length of follow-up for the moderate hypothermia group was $7 \cdot 2$ years, for the profound hypothermia group 4.6 years, and for the cardiopulmonary bypass group 3.4 years.

There were five late deaths. All five patients were over the age of 60 years at the time of their death (average 63 years) and four of the five were in atrial fibrillation and congestive cardiac failure preoperatively. The earliest death occurred in a 61year-old woman in whom a quadriplegia was noted following operation under moderate hypothermia. She died four months later from neurological deficit. The second death occurred in a 65-year-old man nine months postoperatively from myocardial infarction. He had been symptom-free until his death. Another 61-year-old man died from congestive cardiac failure five years after operation. Postoperatively his exercise tolerance had considerably improved compared with his preoperative state. The fourth death occurred in a 60-year-old man 10 years postoperatively from myocardial infarction. Up to his death he had led a normal life. The remaining late death occurred in a 66-year-old man from cor pulmonale 11 years following operation. It is not known whether his cor pumonale resulted from lung disease or pulmonary vascular disease.

COMPlCations Postoperative complications occurred in 75 patients (72\%) leading to 10 early deaths and one late death. Twenty-nine patients $(28 \%)$ had an uneventful postoperative course.

Rhythm disturbances: (a) preoperative sinus rhythm group of 70 patients from all groups surviving operations who were in sinus rhythm preoperatively, $35(50 \%)$ developed arrhythmias postoperatively, including atrial fibrillation (29 patients), atrial flutter (4 patients), and nodal rhythm (2 patients). Sixteen of these reverted to sinus rhythm spontaneously, 13 required DC defibrillation, and one converted after quinidine therapy, leaving five patients still in a dysrhythmia at follow-up. Five others who had been successfully converted postoperatively developed atrial fibrillation 2 to 12 (average 7) years later. (b) Preoperative dysrhythmic group of 24 음 patients surviving operation who were in estab- $\frac{\bar{c}}{\bar{T}}$ lished dysrhythmias preoperatively, six were in $\stackrel{\varnothing}{\varnothing}$ sinus rhythm at late follow-up 1 to 8 years (average 5 years) later, four having converted with ${ }_{\vec{\rho}}^{\text {s }}$ quinidine therapy and two spontaneously.

Neurological disturbances Eleven patients (10.6\%) developed neurological abnormalities postopera- $\vec{x}$ tively. Seven of these were minor episodes consisting of transient hallucinations, delusions, andi. inco-ordination of movement. Four of these were $i$ operated upon under moderate hypothermia and $\forall$ two under cardiopulmonary bypass. The averageo age of this group was 45 years. None had systemic hypertension and all recovered fully before leaving hospital.

In four patients a major cerebral incident $\stackrel{\overrightarrow{\mathbb{D}}}{\overrightarrow{3}}$ occurred. All four patients were over the age of 55 and one had systemic hypertension. One failed to regain consciousness following cardiopul- $\overrightarrow{0}$ monary bypass and died on the sixth postopera-N tive day. The other three occurred following moderate hypothermia. One of these died fouro months postoperatively from cerebral damage while the remaining two survived, although witho residual neurological deficit.

Thromboembolic episodes Clinical thrombo- $\overline{\bar{a}}$ embolic phenomena were recorded in 15 patients. Seven patients developed clinical deep vein throm $=$ bosis, leading to venous gangrene of the toes in one. Clinical pulmonary infarction occurred in $\vec{\sigma}$ six patients, all of whom survived. A further patient developed an axillary vein thrombosis. $\frac{\times}{-}$ Peripheral arterial emboli occurred in two cases, including an aortic saddle embolus and a mesenteric artery, both requiring surgical intervention. The patient developing the saddle embolus was in sinus rhythm while the other occurred in $a^{\text {? }}$ patient with atrial fibrillation.

Haemorrhage Four patients were returned to thễ theatre for further haemostasis and all survived N Three of these had been operated upon using cardiopulmonary bypass and the fourth using moderate hypothermia. A retroperitoneal haemorrhage in one patient and cardiac tamponade in another were directly attributable to postopera ? tive anticoagulant therapy.

Reopening of defect Three patients in the्ग secundum group were noted to have a recure rence of their defect six days, four months, and one year, following operation. Two of these 
patients had their defects successfully closed at a second operation without mortality. The third has refused a further operation.

\section{RESULTS AT LATE FOLLOW-UP}

Seventy-five patients were symptom-free and leading normal lives at late follow-up. This group includes 63 patients in the secundum group, three in the ostium primum group, and nine in the sinus venosus group.

Fourteen patients were symptomatic including nine with exertional dyspnoea. Four of these patients had improved, four were the same, and one was worse compared with their preoperative level of exercise tolerance. The patient who is worse still has his atrial septal defect open as well as a malabsorption syndrome resulting from bowel resection necessitated by a mesenteric artery embolus. He refuses a further operation.

Two have had recurrent chest pains since operation but otherwise normal exercise tolerance. Two have residual hemiplegias and one is under treatment for psychosis.

\section{DISCUSSION}

Although the majority of children with atrial septal defect are symptom-free there is an increasing incidence of symptoms with advancing age (Markman et al., 1965).

Campbell et al. (1957) found that of those patients attending hospital who had not had their atrial septal defects closed only half were still well at 40 and less than a quarter at 50 years of age. This deterioration most frequently occurs in association with a dysrhythmia, usually atrial fibrillation, following which the heart rapidly enlarges. Tricuspid regurgitation and heart failure soon become evident (Wood, 1962).

Pulmonary hypertension has been noted with a greater frequency in older patients with atrial septal defect than in those under the age of 40 (Markman, et al., 1965), and Gault, Morrow, Gay, and Ross (1968) demonstrated a clear relationship between pulmonary hypentension and degree of disability.

The reported average age of death in patients with atrial septal defect ranges from 36 years (Roesler, 1934) to 49 years (Cosby and Griffith, 1949).

To prevent the development of these late sequelae, surgical closure of the defect in childhood has become established practice. The mortality rate associated with operation in this younger age group is sufficiently low to recom- mend closure of medium and larger defects, even in the absence of symptoms (Cleland, Goodwin, McDonald, and Ross, 1969).

However, Wolf and his colleagues (1968), while agreeing that operation in the younger patient with atrial septal defect is advisable, suggest that the role of surgery in the middle-aged patient is uncertain. Reviewing 34 patients over the age of 45 , of whom 15 underwent surgery, they concluded that surgery offers the greatest benefit to the progressively symptomatic adult with normal or mild to moderate increases in pulmonary artery pressures, and that operation in those with severe pulmonary hypertension is too hazandous. In a study of 48 surgically treated patients with atrial septal defect in this age group, Gault and his coworkers (1968) concluded that, despite the presence of pulmonary hypertension and congestive failure, operative closure could be undertaken with low operative mortality, with sustained clinical and haemodynamic benefit in the survivors.

In this series the overall hospital mcrtality rate was $9.6 \%$, reducing to $2.7 \%$ in the last six years studied. This reduction in mortality rate is comparable with that observed in other centres (Gault et al., 1968 ; Daicoff, Brandenburg, and Kirklin, 1967) and appears to be a reflection of improved operative technique and postoperative care with experience, rather than to patient selection. It is interesting to note that the mortality following hypothermia was double that following cardiopulmonary bypass and that of the three deaths following the latter technique the one due to quinidine therapy was potentially avoidable. Analysis of the five late deaths shows that the average age of the patients was 63 years and that four of the five had derived considerable benefit from the operation. With regard to the effect of preoperative pulmonary hypertension, it may be noted that a moderate increase in pulmonary artery pressure (up to $60 \mathrm{mmHg}$ systolic) did not significantly increase the overall hospital mortality. In the seven patients with pulmonary artery pressures above $60 \mathrm{mmHg}$ systolic, there were two deaths which would tend to suppont the contention of Wolf and his colleagues (1968) that operation in patients with severe pulmonary hypertension is too hazardous. However, both of these deaths occurred following hypothermia in 1958 and since that time there has been no mortality in five patients in this group (average systolic pulmonary artery pressure of $72 \mathrm{mmHg}$ ).

Dysrhythmias are common in elderly patients with atrial septal defects. In this series, although these dysrhythmias were frequent in the postopera- 
tive period, of those patients in sinus rhythm before operation only 7\% left hospital in atrial fibrillation. Another 7\% have since developed atrial fibrillation an average of seven years after operation.

However, $25 \%$ of patients who were in atrial fibrillation before operation have been maintained in sinus rhythm an average of five years following operation. It would appear that closure of the defect has a beneficial effect in preventing dysrhythmias.

At their last attendance 75 patients were symtom-free and, of those who were symptomatic, only five had obtained no subjective benefit from the operation.

It is concluded from this study that recent advances in surgical and cardiopulmonary bypass techniques and improved postoperative care have decreased the mortality and morbidity of operation to the extent that surgical closure of atrial septal defects at any age is now justified, even in the presence of pulmonary hypertension.

We should like to thank Mr. W. P. Cleland, Mr. M. Paneth, and Mr. O. S. Tubbs of the Brompton Hospital for allowing us to study their patients.

\section{REFERENCES}

Barratt-Boyes, B. G. (1963). The results of repair of atrial septal defect using the atrial well method. Ann. roy. Coll. Surg. Engl., 33, 209.
Burrett, J. B., and White, P. D. (1945). Large interauricular septal defect with particular reference to diagnosis and $\frac{\bar{\sigma}}{\bar{S}}$ longevity. Report of 2 new cases. Amer. J. med. Sci., 209, 355

Campbell, M., Neill, C., and Suzman, S. (1957). The prog-ळ nosis of atrial septal defect. Brit. med. J., 1, 1375.

Cleland, W., Goodwin, J., McDonald, L., and Ross, D. (1969). Atrial septal defect and anomalies of venous $\vec{\omega}$ return. In Medical and Surgical Cardiology, p. 449. Blackwell Scientific Publications, Oxford.

Cohn, L. H., Morrow, A. G., and Braunwald, E. (1967). Operative treatment of atrial septal defect: clinical and $V$ haemodynamic assessments in 175 patients. Brit. Heartic J., 29, 725.

Cosby, R. S., and Griffith, G. C. (1949). Interatrial septal Vᄀ defect. Amer. Heart J., 38, 80.

Daicoff, G. R., Brandenburg, R. O., and Kirklin, J. W. (1967). Results of operation for atrial septal defect in $\overrightarrow{C S}$ patients 45 years of age and older. Circulation, 35, $\mathbb{D}$ Suppl. 1, p. 143.

Gault, J. H., Morrow, A. G., Gay, W. A., and Ross, J. (1968). Atrial septal defect in patients over the age of 40 years. Circulation, 37, 261.

Markman, P., Howitt, G., and Wade, E. G. (1965). Atrial $\overrightarrow{0}$ septal defect in the middle-aged and elderly. Quart. J. N Med., 34, 409.

Roesler, H. (1934). Interatrial septal defect. Arch. intern. Med., 54, 339.

Wolf, P. S., Vogel, J. H. K., Pryor, R., and Blount, S. G. Jr. (1968). Atrial septal defect in patients over 45 years of age. Merits of surgical versus medical therapy. Brit. $\frac{\mathrm{D}}{\mathrm{D}}$ Heart J., 30, 115.

Wood, P. (1962). III. Fate of the child with unrelieved con- $\overrightarrow{\vec{A}}$ genital heart disease. Atrial septal defect. In Congenital Heart Disease: An International Symposium, edited by D. P. Morse, p. 49. Blackwell Scientific Publications, Oxford. 